\title{
INVESTIGACIÓN
}

Recibido: 21/05/2019 --- Aceptado: 02/07/2019 --- Publicado: 15/03/2020

\section{LA RESPONSABILIDAD SOCIAL DE LA PUBLICIDAD: EL ROL DE LAS CAMPAÑAS DE BIEN PÚBLICO}

\author{
The social responsibility of advertising: the role of public property campaigns
}

(D) 8 Carolina Tomba ${ }^{1}$. Universidad Juan Agustín Maza. Argentina.

ctomba@umaza.edu.ar

Cecilia Muñoz. Universidad Juan Agustín Maza. Argentina.

cmunoz@umaza.edu.ar

Andrés Allisiardi. Universidad Juan Agustín Maza. Argentina. allisiardi@umaza.edu.ar

\section{RESUMEN}

La publicidad forma actitudes y transmite valores, su masividad la transforma en referente para la sociedad. Nuestro trabajo resulta de una investigación acerca de la efectividad de las campañas de bien público, tipología publicitaria caracterizada por la difusión de mensajes para lograr una mejor calidad de vida. Nuestro proyecto incorpora al debate el rol de las campañas publicitarias en su concepción social. Nuestro objetivo principal es determinar cuáles recursos, estilos y enfoques son pertinentes para comunicar responsable y efectivamente las problemáticas sociales. Adoptamos un diseño metodológico no experimental, y abordamos el estudio a través de técnicas de recolección de datos cuali-cuantitativas. Analizamos todas las campañas y paralelamente realizamos un análisis social para comprender el contexto. Sometimos la muestra a un análisis de contenido para el estudio de la construcción de los mensajes, a través de la tabla Ecrep para evaluar los niveles de creatividad, donde ninguna de las campañas superó el nivel bajo de creatividad; y desarrollamos tres Focus Group para analizar el impacto y comprensión del mensaje y para obtener información de la claridad comunicacional, pero hubo coincidencias en que la mayoría de las piezas pasa desapercibida. En cuanto a la preferencia de los medios, los audiovisuales son los más elegidos. Validamos nuestra hipótesis evidenciando que las campañas de bien público argentinas no cuentan con los recursos creativos necesarios para garantizar su eficacia. La publicidad de bien público debería desarrollarse con parámetros máximos de eficacia, para no perder su esencia y lograr contribuir a la mejora del colectivo social.

\footnotetext{
${ }^{1}$ Carolina Tomba: Licenciada en Comunicación Social y Especialista en Docencia de Nivel Superior, desarrollando la Tesis de Maestría en Docencia en Nivel Superior.
} 
PALABRAS CLAVE: publicidad - bien público - responsabilidad - eficacia creatividad - persuasión - agenda social.

\begin{abstract}
Advertising forms and creates attitudes and transmits values, its massiveness transforms it into a reference for the community. Our work comes from a research about the effectiveness of public welfare campaigns, advertising typology characterized by the broadcasting of messages to achieve a better quality of life. Our project incorporates the debate about advertising campaigns' role in its social conceptions. Our main objective is to determinate which resources, styles and approaches are relevant to communicate social issues in a responsible and effective way. This study has a non-experimental methodological design, and we used qualiquantitative collection of data techniques. We analyzed all the campaigns and the same time we did a social analysis to comprehend the context. We submitted the sample to an analysis of content to study the messages construction trough the Ecrep table to evaluate the creativity levels, none of the campaigns exceed the low creativity levels; three Focus Groups were developed to analyze the impact and comprehension of the message and to get information about the communicational clarity, there were coincidences that most of the pieces went unnoticed. Regarding the media preferences, the audiovisuals are the most chosen. We validate the hypothesis by showing that Argentinian public welfare campaigns don't have the essential creative resources needed to assure its efficiency. Welfare advertising should be developed with high efficiency parameters in order not to lose its essence and to contribute to the improvement of the social community.
\end{abstract}

KEY WORDS: advertising - welfare - responsability - efficiency - creativity persuasion - social agenda.

\title{
A RESPONSABILIDADE SOCIAL DA PUBLICIDADE: O PAPEL DAS CAMPANHAS DE BEM PÚBLICO
}

\section{RESUME}

A publicidade forma atitudes e transmite valores, sua intensidade há transforma em referente para a sociedade. Nosso trabalho resulta de uma investigação sobre a efetividade das campanhas de bem público, tipologia publicitaria caracterizada pela difusão de mensagens para conseguir uma melhor qualidade de vida. Nosso projeto incorpora o debate do papel das campanhas publicitarias em sua concepção social. Nosso objetivo principal e determinar quais recursos, estilos e enfoques são pertinentes para comunicar responsável e efetivamente as problemáticas sociais. Adoptamos um desenho metodológico não experimental, e abordamos o estudo através de técnicas de recolecção de dados quali-quantitativas. Analisamos todas as campanhas e paralelamente realizamos uma analises social para compreender o contexto. Submetemos a amostra a uma analises de conteúdo para o estudo da 
construção das mensagens, através da tabela Ecrep para valorar os níveis de criatividade, onde nenhuma das campanhas superou o baixo nível de criatividade; e desenvolvemos três Focus Group para analisar o impacto e compreensão da mensagem e para obter informação da claridade comunicacional, mais ouve coincidências em que a maioria das peças passa desapercebida. Enquanto a preferência dos meios, os audiovisuais são os mais elegidos. Validamos nossa hipótese evidenciando que as campanhas do bem público argentinas não contam com os recursos criativos necessários para garantir sua eficácia. A publicidade do bem público deveria desenvolver-se com parâmetros máximos de eficácia, para não perder sua essência e conseguir contribuir com a melhora do coletivo social.

PALAVRAS CHAVE: publicidade - bem público - responsabilidade - eficácia criatividade - persuasão - agenda social.

\section{Como citar el artículo:}

Tomba, C.; Muñoz, C. y Allisiardi, A. (2020). La responsabilidad social de la publicidad: el rol de las campañas de bien público. [The social responsibility of advertising: the role of public property campaigns].Vivat Academia. Revista de Comunicación, 150, 103-129.

doi: http:/ / doi.org/10.15178/va.2020.150.103-129

Recuperado de http:// www.vivatacademia.net/index.php/vivat/article/view/1190

\section{INTRODUCCIÓN}

Es innegable el rol de la publicidad en la construcción del imaginario social. Su naturaleza persuasiva la convierte en formadora de actitudes y transmisora de valores, y su masividad la transforma en un importante referente para la sociedad. En las primeras décadas del siglo XXI se ha consolidado como una de las herramientas más eficaces para contribuir al cambio social. (Alvarado López, 2009, p. 280).

En los estudios sobre su influencia, existe un tema que ha sido históricamente relegado, o tratado superficialmente: su contribución en la toma de conciencia sobre problemáticas sociales. La necesidad de iniciar una reflexión sobre sus aspectos esenciales: temática, la estructura comunicacional a partir de la cual se desarrolla y el papel que está cumpliendo en nuestras sociedades (Alvarado López, 2009, p. 265). El estudio más completo sobre la temática es la publicación del Consejo Publicitario Argentino: "La publicidad de Bien Público: el impacto de la comunicación social" (Consejo Publicitario Argentino, 2011) que agrupa y analiza casos que fueron exitosos a lo largo de la historia.

“La publicidad social no es simplemente una moda o tendencia pasajera (...) es una necesidad para la sociedad y para la actividad publicitaria en sí misma" (Alvarado López, 2009, p. 279). 
Esta investigación se propuso analizar desde lo comunicacional y creativo las campañas publicitarias de bien público para determinar los recursos más eficientes que colaboren con la mejora en la calidad de vida del colectivo social.

\section{OBJETIVOS}

General: Analizar y establecer cuáles son los recursos comunicacionales y creativos que logran el mayor impacto en las campañas publicitarias de bien público para la toma de conciencia de la problemática social que comunican.

Específicos: Analizar la publicidad de bien público difundida en la provincia de Mendoza en el período 2016-2018. Analizar el contexto. Determinar los temas prioritarios en la Agenda Social. Estudiar y determinar los parámetros comunicacionales y creativos de mayor impacto para este tipo de comunicación. Analizar la percepción y decodificación de los diferentes públicos.

\section{METODOLOGÍA}

Estudiamos todas las campañas publicitarias de bien público difundidas en la provincia de Mendoza en el período 2016-2018, 8 en total, poniendo el foco en las temáticas prioritarias de la Agenda social y en el principal emisor de este tipo de mensajes: el gobierno provincial.

A la muestra se la sometió en primera instancia a un análisis de contenido para el estudio de los mensajes comunicados en cada una de las campañas, observando los conceptos comunicados es decir las ideas básicas a partir de la cual se estructuran las piezas, los géneros y estilos publicitarios utilizados y todos los elementos de significación: tipografía, colores, imágenes, música desde una perspectiva denotativa y connotativa. Es tarea del análisis cualitativo el poder describir los elementos de ciertas conductas, registrarlos de forma ordenada, clasificarlos o categorizarlos, determinar su frecuencia cuantitativa e interrelaciones. Posteriormente y para medir los niveles de creatividad se aplicó la tabla Ecrep (Vejling; Tomba; Mateo, 2011, p. 86) resultado del proyecto de investigación "Evaluación de la creatividad publicitaria: generación de instrumentos de medición para aplicar a las publicidades" que evalúa la pieza a partir de los siguientes parámetros: originalidad; impacto; utilización de analogías o de relaciones únicas; provocación de la fantasía y la imaginación; generación de emociones o sensaciones positivas. 
Tomba, C.; Muñoz, C. y Allisiardi, A.

La responsabilidad social de la publicidad: el rol de las campañas de bien público

Tabla ECREP

para evaluar la creatividad en un anuncio

\begin{tabular}{|c|c|c|c|c|c|}
\hline & $\stackrel{1}{\perp}$ & $\stackrel{2}{\perp}$ & $\stackrel{3}{\perp}$ & 4 & $\stackrel{5}{\perp}$ \\
\hline \multirow[t]{3}{*}{ ORIGINALIDAD } & $\begin{array}{c}\text { Copia todos o la may oria de los recursos } \\
\text { que ya han sido usados en otros } \\
\text { anuncios conocidos. }\end{array}$ & $\begin{array}{l}\text { Copia ciertos recursos ya vistos con } \\
\text { frecuencia en otros anuncios. }\end{array}$ & $\begin{array}{l}\text { Posee algunos recursos que, por su } \\
\text { rareza, son diferenciadores. }\end{array}$ & $\begin{array}{l}\text { Posee muchos recursos que, por su } \\
\text { rareza, son diferenciadores y hacen del } \\
\text { anuncio algo fuera de lo común. }\end{array}$ & $\begin{array}{l}\text { Se aparta totalmente de lo previsible y } \\
\text { conocido, siendo único en su categoria. } \\
\text { Logra establecer un nuevo parámerto. }\end{array}$ \\
\hline & NULO NIVEL DE ORIGINALIDAD & BAJO NIVEL DE ORIGINALIDAD & $\begin{array}{l}\text { MEDIANO NIVEL DE } \\
\text { ORIGINALIDAD }\end{array}$ & ALTO NIVEL DE ORIGINALIDAD & $\begin{array}{l}\text { MUY ALTO NIVEL DE } \\
\text { ORIGINALIDAD }\end{array}$ \\
\hline & $\stackrel{1}{\perp}$ & $\stackrel{2}{\perp}$ & $\stackrel{3}{\perp}$ & 4 & $\stackrel{5}{\perp}$ \\
\hline \multirow[t]{2}{*}{ CONECTIVIDAD } & No conecta ideas, no hace analogias. & $\begin{array}{l}\text { Conecta ideas cuya relación entre si es } \\
\text { común o predecible. }\end{array}$ & $\begin{array}{l}\text { Intenta conectar ideas cuya relación entre } \\
\text { si es poco común o poco predecible } \\
\text { (distantes). }\end{array}$ & $\begin{array}{c}\text { Conecta ideas cuya relación entre si no } \\
\text { es predecible ni evidente. }\end{array}$ & $\begin{array}{c}\text { Conecta ideas que no tienen relación } \\
\text { evidente o aparente y lo hace de forma } \\
\text { muy novedosa, generando sorpresa y } \\
\text { admiración. }\end{array}$ \\
\hline & NULO NIVEL DE CONECTIVIDAD & BAJO NIVEL DE CONECTIVIDAD & $\begin{array}{l}\text { MEDIANO NIVEL DE } \\
\text { CONECTIVIDAD }\end{array}$ & ALTO NIVEL DE CONECTIVIDAD & $\begin{array}{l}\text { MUY ALTO NIVEL DE } \\
\text { CONECTIVIDAD }\end{array}$ \\
\hline
\end{tabular}

\begin{tabular}{|c|c|c|c|c|c|}
\hline \multirow{2}{*}{ LÓGICA } & $\begin{array}{c}\text { No es posible decodifcarlo, debido a la } \\
\text { complejidad que manifesta. }\end{array}$ & $\begin{array}{c}\text { Resuelve la conexión de ideas distantes } \\
\text { entre si, pero la lógica de conexión es } \\
\text { bastante predecible. }\end{array}$ & $\begin{array}{c}\text { Resuelve la conexión de ideas desde } \\
\text { una lógica compleja, lo que dificulta su } \\
\text { decodificación. }\end{array}$ & $\begin{array}{c}\text { Resuelve de muy buena forma la } \\
\text { conexión de ideas distantes entre sí, } \\
\text { permitiendo entender la nueva lógica de } \\
\text { conexión. }\end{array}$ & $\begin{array}{l}\text { Hace excelente conexión entre ideas que } \\
\text { son remotas entre si, haciendo entendible } \\
\text { totalmente la nueva lógica de conexión. }\end{array}$ \\
\hline & NULO NIVEL DE LÓGICA & BAJO NIVEL DE LÓGICA & MEDIANO NIVEL DE LÓGICA & ALTO NIVEL DE LÓGICA & MUY ALTO NIVEL DE LÓGICA \\
\hline
\end{tabular}

\begin{tabular}{|c|c|c|c|c|c|}
\hline \multirow{2}{*}{ IMPACTO } & $\begin{array}{c}\text { No logra la movilización del mundo } \\
\text { interno del perceptor. }\end{array}$ & $\begin{array}{c}\text { Tene unos pocos recursos que logran } \\
\text { movilizar débilmente el mundo interno del } \\
\text { perceptor. }\end{array}$ & Moviliza el mundo interno del receptor. & $\begin{array}{c}\text { Logra un golpe emocional en el receptor } \\
\text { que moviliza su mundo interno. }\end{array}$ & $\begin{array}{c}\text { Logra un fuerte golpe emocional en el } \\
\text { receptor que conmueve } \\
\text { significativamente su mundo interno. }\end{array}$ \\
\hline & NULO NIVEL DE IMPACTO & BAJO NIVEL DE IMPACTO & MEDIANO NIVEL DE IMPACTO & ALTO NIVEL DE IMPACTO & MUY ALTO NIVEL DE IMPACTO \\
\hline
\end{tabular}

\begin{tabular}{|c|c|c|c|c|c|}
\hline & $\stackrel{1}{\perp}$ & $\stackrel{2}{\perp}$ & $\stackrel{3}{1}$ & $\stackrel{4}{\perp}$ & $\stackrel{5}{\perp}$ \\
\hline EMOTIVIDAD & $\begin{array}{l}\text { Genera sensaciones y/o emociones que } \\
\text { el público objetivo rechaza. }\end{array}$ & $\begin{array}{l}\text { No genera ningún tipo de sensación y/o } \\
\text { emoción en el público objetivo. }\end{array}$ & $\begin{array}{l}\text { Genera sensaciones y/o emociones con } \\
\text { las que el público objefivo se idenfifica } \\
\text { livianamente o no se identifica. }\end{array}$ & $\begin{array}{c}\text { Genera sensaciones y/o emociones con } \\
\text { las que el público objetivo se identifica } \\
\text { positivamente. }\end{array}$ & $\begin{array}{c}\text { Genera intensas sensaciones y/o } \\
\text { emociones con las que el público objetivo } \\
\text { se identifica fuerte y positivamente. }\end{array}$ \\
\hline & NULO NIVEL DE EMOTIVIDAD & BAJO NIVEL DE EMOTIVIDAD & $\begin{array}{l}\text { MEDIANO NIVEL DE } \\
\text { EMOTIVIDAD }\end{array}$ & ALTO NIVEL DE EMOTIVIDAD & $\begin{array}{l}\text { MUY ALTO NIVEL DE } \\
\text { EMOTIVIDAD }\end{array}$ \\
\hline
\end{tabular}

\begin{tabular}{|c|c|c|c|c|c|}
\hline & $\stackrel{1}{\perp}$ & $2^{2}$ & $\stackrel{3}{1}$ & $\stackrel{4}{\perp}$ & $\stackrel{5}{\perp}$ \\
\hline \multirow[t]{2}{*}{ FANTASÍA } & $\begin{array}{c}\text { Provoca que el perceptor no complete } \\
\text { con su imaginación el mundo de fantasia } \\
\text { que le está ofreciendo. }\end{array}$ & $\begin{array}{c}\text { Provoca que el perceptor complete con } \\
\text { su imaginación el mundo de fantasia que } \\
\text { le está ofreciendo, pero separándolo de la } \\
\text { marca o producto. }\end{array}$ & $\begin{array}{l}\text { Provoca que el perceptor complete con } \\
\text { su imaginación el mundo de fantasia que } \\
\text { le está ofreciendo, en una débil relación } \\
\text { con la marca o producto. }\end{array}$ & $\begin{array}{c}\text { Provoca que el perceptor complete con } \\
\text { su imaginación y que incluya la marca o } \\
\text { producto al mundo de fantasia que le está } \\
\text { ofreciendo. }\end{array}$ & $\begin{array}{l}\text { Provoca que el perceptor complete con } \\
\text { su imaginación y haga una perfecta } \\
\text { sinergia entre el producto o marca y el } \\
\text { mundo de fantasia que le está ofreciendo. }\end{array}$ \\
\hline & NULO NIVEL DE FANTASÍA & BAJO NIVEL DE FANTASÍA & MEDIANO NIVEL DE FANTASÍA & ALTO NIVEL DE FANTASÍA & MUY ALTO NIVEL DE FANTASÍA \\
\hline
\end{tabular}

\begin{tabular}{|c|c|c|c|}
\hline QUIEBRE & Es convencional el medio y/o soporte. & $\begin{array}{c}\text { Aporta algún elemento nuevo el medio } \\
\text { y/o soporte. }\end{array}$ & Logra innovar en el medio y/o soporte. \\
\hline
\end{tabular}

\begin{tabular}{|l|}
\hline Escala de Resultados \\
Nulo Nivel de Creatividad: de 5 a 11 puntos \\
Bajo Nivel de Creatividad: de 12 a 17 puntos \\
Mediano Nivel de Creatividad: de 18 a 23 puntos \\
Alto Nivel de Creatividad: de 24 a 29 puntos \\
Muy Alto Nivel de Creatividad: de 30 a 35 puntos \\
\hline
\end{tabular}

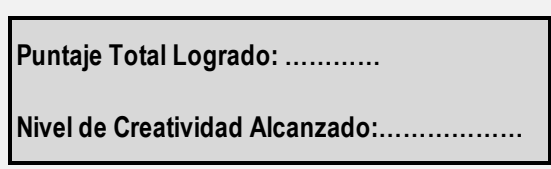

Foto 1. Instrumento de investigación. Tabla Ecrep: Medición creatividad.

Fuente: Vejling, Tomba, Mateo 2011.

En tercer lugar, se desarrollaron Focus Group con el objetivo de evaluar el impacto, la comprensión del concepto comunicado y toma de conciencia de la problemática específica. Buscamos comprender cuál es la reacción del público frente a este tipo de 
comunicación. Los participantes fueron seleccionados de forma aleatoria y voluntaria en función del público objetivo de las campañas. Edad: 18-65 años; nivel socio económico: clase media en sus tres gradientes; nivel educativo: secundario completo e incompleto, universitario completo e incompleto; residentes de la provincia de Mendoza, Argentina.

\section{DISCUSIÓN}

Tal como se describe en la metodología presentamos el análisis de cada campaña desde tres abordajes: análisis del contexto social, análisis de contenido y niveles de creatividad. Al finalizar este análisis se expondrán los resultados del Focus Group. Por razones de espacio se expone una sola pieza de cada una de las campañas.

Es pertinente aclarar que el idioma de las campañas es español o castellano rioplatense, por lo tanto, existen algunas características propias de acentuación que, en cada caso serán aclaradas.

\subsection{Campaña $n^{0} 1$}

\subsubsection{Datos técnicos}

1. Nombre de la campaña: Familia Temporaria. Año: 2017. https://www.facebook.com/FamiliaTemporaria/videos/288720908250548/

2. Categoría: SOCIEDAD.

3. Objetivo: persuadir al target para sumarse como "familias voluntarias" y así brindarle un hogar transitorio a niños que atraviesan situaciones judiciales.

4. Target: familias mendocinas que tengan hijos o que hayan tenido experiencia en el cuidado de niños, y que cuenten con un hogar y tiempo de dedicación.

\subsubsection{Análisis del contexto}

No todos los niños con vulnerabilidad que se encuentran en las instituciones de guarda, están en condiciones de ser adoptados pues hay tiempos que se respetan para intentar reconstruir los lazos familiares. En Mendoza, se lleva adelante un programa sistemático para refuncionalizar el sistema de adopción en la provincia. El artículo de Adriana Lui (2017), en el diario El Sol, explica la situación.

El plan de la Subsecretaría de Desarrollo Social fue cambiar el paradigma de patronato y trasladó a los menores a micro hogares. Esto permitió que los niños puedan vivir en un mejor contexto y desarrollar su autoestima e identidad al compartir su espacio con menos personas. Pero, tuvo como consecuencia que algunos hermanos fueran separados. (Lui, 2017, párr.1)

La Asociación de voluntarios de Mendoza (AVOME) se encarga de llevar adelante el programa de Familia temporaria de Mendoza y lo define de la siguiente manera: 
Se trata de familias que no presentas lazos de parentesco con el niño o niña y que se abren a la posibilidad de brindarle un ambiente familiar por un tiempo hasta que se resuelva la situación legal del niño. Es claro que la familia temporaria tiene un carácter transitorio. Los tiempos son variables, dependiendo de cada caso. (AVOME, 2017, párr.5)

En 2017 sólo 28 familias realizaron este tipo de acompañamiento y el Gobierno provincial apuntó a una fuerte campaña para lograr la meta de triplicar el número.

\subsubsection{Análisis de contenido}

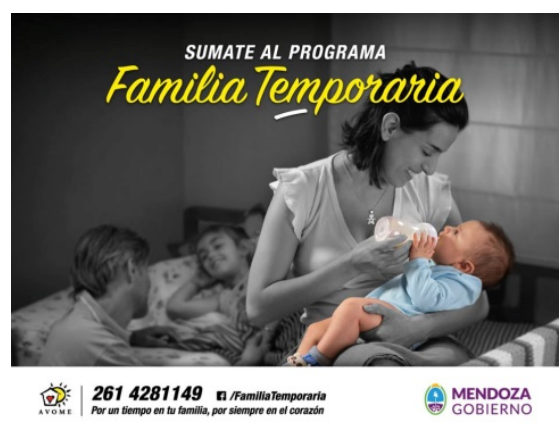

Foto 2. Campaña: Familia Temporaria. Pieza de vía pública.

Fuente: Gobierno de Mendoza.

Las piezas optan por el empleo de la fotografía como principal recurso para comunicar el concepto, así se consigue representar con gran realismo una situación de emotividad positiva. Se retrata una situación cotidiana que busca despertar la identificación, el valor cromático de la imagen tiene un rol central: por un lado, el empleo de la escala de grises junto a un ligero desenfoque, por el otro proyecta la figura en color lo cual posibilita destacar su felicidad y materializa la promesa de campaña. El titular decide hablarle de forma directa al público resuelto en dos bloques combina tipografía sin serif itálica con caligráfica en color amarillo, logrando calidez y dinamismo. Un pequeño subrayado se sitúa sobre la palabra "temporaria", destacando el carácter transitorio de la ayuda. En las redes sociales las piezas rescatan los mismos elementos compositivos para presentar una variación en las situaciones representadas. Para la televisión se utiliza el género testimonial para comunicar las vivencias de los protagonistas, una sucesión de planos medios y primeros permite conocer el relato de tres familias que formaron parte del programa. La banda sonora instrumental brinda un ambiente positivo, sin recaer en una hipersensibilización del mensaje. La voz de los protagonistas se ve subrayada por planos que muestran sus manos y su expresión facial, buscando darle fuerza al testimonio. De esta forma, las familias enumeran los múltiples beneficios en la vida de los chicos que albergaron: mayor autoestima y sentido de pertenencia. 


\subsubsection{Análisis del nivel de creatividad: tabla Ecrep}

1. Originalidad: mediano ( $3 \mathrm{p})$. Posee algunos recursos que por su rareza son diferenciadores. Principalmente el color utilizado en las gráficas.

2. Conectividad: bajo ( $2 \mathrm{p})$. Conecta ideas cuya relación entre sí es común o predecible. Esto se puede ver en el uso de imágenes de distintos tipos de familias.

Lógica: bajo ( 2 p). Resuelve la conexión de ideas distantes entre sí, pero la lógica de conexión es bastante predecible. Esto se ve reflejado en un enfoque referencial de las imágenes.

Impacto: bajo ( $2 \mathrm{p}$ ). Tiene pocos recursos que logran movilizar débilmente el mundo interno del perceptor. Los recursos se articulan desde un planteo que brinda estética y contraste visual, sin generar impacto de manera significativa.

1. Emotividad: mediano (3 p). Genera sensaciones y/o emociones con las que el público objetivo se identifica livianamente o no se identifica. La campaña intenta movilizar al target, pero lo hace desde situaciones estandarizadas que no logran llegar a sus fibras emocionales.

2. Fantasía: nulo (1 p). Provoca que el perceptor no complete con su imaginación el mundo de fantasía que se le está ofreciendo.

3. Quiebre (1 p): Es convencional el medio y/o soporte: spot publicado en redes sociales y gráficas en vía pública, diarios y revistas de la provincia y redes.

Resultados: Puntaje: 14 puntos. Nivel de creatividad alcanzado: Bajo.

\subsection{Campaña $n^{\circ} 2$}

\subsubsection{Datos técnicos}

1. Nombre de la campaña: Terminemos con el acoso. Año: 2017.

2. Categoría: SOCIEDAD.

3. Objetivo: concientizar al target sobre la problemática del acoso callejero como una forma de ejercer violencia de género.

4. Concepto: el acoso callejero es violencia.

5. Target: hombres y mujeres desde los 15 años de todos los niveles socioeconómicos.

\subsubsection{Análisis del contexto}

Para definir acoso callejero tomamos la adoptada por el Primer informe del Observatorio de violencia contra las mujeres "Ni una Menos", de Argentina:

toda conducta $\mathrm{u}$ acción, física o verbal, con connotación sexual y no deseadas, realizada por una o más personas en contra de toda mujer o persona que se auto perciba como mujer, llevada adelante en lugares o espacios públicos, o de acceso público, que de manera directa o indirecta afecten y/o perturben su vida, dignidad, libertad, integridad física y/o psicológica y/o el libre tránsito, 
creando en ellas intimidación, hostilidad, degradación, humillación y/o un ambiente ofensivo en los espacios públicos, siempre y cuando no configure un delito más severamente penado. (Vivanco, 2017, p. 28)

Esta problemática es una de las más naturalizadas y aceptadas por la sociedad y que requiere el desarrollo de políticas de Estado que ayuden a aminorar los efectos en contra de las mujeres.

En Mendoza existe la Dirección de Género y Diversidad, dentro de la Subsecretaría de Desarrollo Social, cuyos objetivos son la generación de políticas con perspectiva de género, promoviendo la igualdad de derechos para mujeres y hombres, asistencia a mujeres víctimas de violencia, entre otras. De todas maneras, no se observa dentro de los programas presentados políticas explícitas contra el acoso callejero, solamente noticias en torno a la conmemoración del 7 de abril como día de lucha contra el acoso callejero, en el marco de la fecha propuesta por la Ley 5742 de "Acoso sexual en espacios públicos o de acceso público", dictada por la Legislatura de la Ciudad Autónoma de Buenos Aires, Argentina en 2016.

\subsubsection{Análisis de contenido}

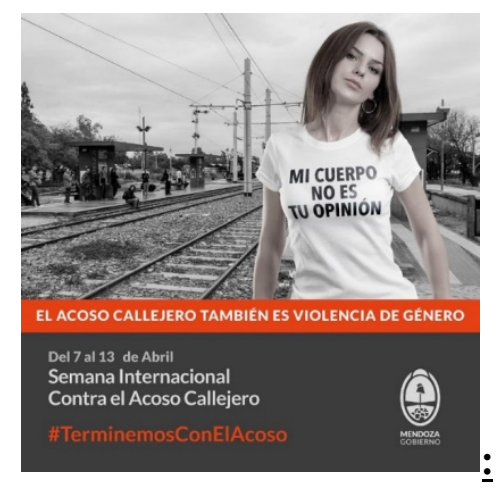

Foto 3. Campaña: Terminemos con el acoso. Pieza para Facebook.

Fuente: Gobierno de Mendoza.

La campaña está integrada por un conjunto seriado de piezas para redes sociales que amparadas por un mismo bloque inferior de texto, muestran una sucesión de hombres y mujeres portadores del mensaje. Este elemento es propuesto como la puerta de entrada al relato los planos medios muestran a los protagonistas con posturas corporales que apoyan la contundencia de las palabras expuestas en carteles y remeras. El uso de la primera persona ayuda a consolidar el tono de denuncia, se busca que los pares puedan desnaturalizar tal conducta hacia el género femenino, planteada como una clara expresión de violencia. Los protagonistas miran a los ojos del target para implicarlo en el mensaje, amparados por escenarios urbanos que ponen en contexto la problemática. Finalmente, el hashtag "TerminemosConElAcoso" se expone para cumplir un doble objetivo: desde la 
propuesta comunicacional, actúa como cierre desde el soporte, motiva al target a interactuar en redes sociales, apoderándose del texto.

\subsubsection{Análisis de los niveles de creatividad: tabla Ecrep}

1. Originalidad: Bajo (2 p). Copia ciertos recursos ya vistos en otros anuncios: la fotografía en blanco y negro, la presencia de personas con carteles a modo de huelga o reclamo.

2. Conectividad: Bajo (2 p). Conecta ideas cuya relación entre sí es común o predecible: calles de la ciudad de Mendoza y la referencia al acoso callejero.

3. Lógica: Bajo (2 p). Resuelve la conexión de ideas diferentes pero la lógica de conexión es bastante predecible: la relación entre los carteles y la presencia de hombres y mujeres.

4. Impacto: Nulo (1 p). No logra la movilización del mundo interno del perceptor siendo una temática actual y que se encuentra latente en los medios como en la realidad del perceptor, su comunicación no provoca el impacto necesario.

5. Emotividad: Mediano (3 p). Genera sensaciones y/o emociones con las que el público objetivo se identifica livianamente o no se identifica: los recursos utilizados no son lo suficientemente fuertes como para generar la reacción buscada y esperada.

6. Fantasía: Nulo (1 p). Provoca que el perceptor no complete con su imaginación el mundo de fantasía que le está ofreciendo: la falta de elementos que remitan a la problemática planteada.

7. Quiebre: (1 p). Es convencional el medio y/o soporte: gráficas publicadas solo a través de redes sociales.

Resultados: Puntaje: 12 puntos. Nivel de creatividad alcanzado: Bajo.

\subsection{Campaña $n^{0} 3$}

\subsubsection{Datos técnicos}

1. Nombre de la campaña: No pasa nada. Año: 2017.

2. Velocidad: https://www.youtube.com/watch?v=cCharbzwtyg Alcohol: https://www.youtube.com/watch?v=VKbiBxkQ444 Celular: https://www.youtube.com/watch?v=i8TQFUsu3XY

3. Categoría: SOCIEDAD/Seguridad vial.

4. Objetivo: Disminuir los accidentes de tránsito provocados por el uso del celular, el consumo de alcohol y el exceso de velocidad.

5. Concepto: responsabilidad en el manejo.

6. Target: hombres y mujeres desde los 18 años de edad. 


\subsubsection{Análisis del contexto}

La seguridad vial es uno de los temas más preocupantes de la sociedad argentina. Las cifras de muertos anuales aumentan cada año. Según un artículo de la Asociación civil Luchemos por la vida (2017), en Argentina:

20 personas mueren por día; hay 7.213 víctimas fatales por año (2017) y unos 120 mil heridos de distinto grado y miles de discapacitados." (Luchemos por la vida, 2017, párr.2). El informe resalta que "los accidentes de tránsito en la Argentina, son la primera causa de muerte en menores de 35 años, y la tercera sobre la totalidad de los argentinos. (Ídem, párr.7)

El Ministerio de Transporte de la Presidencia de la Nación Argentina (2018) expuso en un informe "las motivaciones de los jóvenes entre 16 y 30 años en relación al consumo de alcohol en asociación a la seguridad vial" y pone de relieve tres dimensiones que explican las conductas relacionadas con el alcohol y conducir. La falta de percepción del riesgo; la ausencia del Estado en temas de control; y por último la cultura del alcohol como medio para sociabilizar.

\subsubsection{Análisis de contenido}

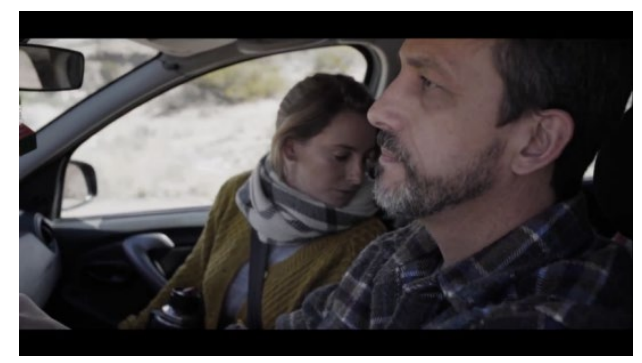

Foto 4. Campaña: No pasa nada hasta que pasa. Aviso de televisión. Fuente: Gobierno de Mendoza.

Los avisos comunican el mensaje desde situaciones cotidianas. El primero inicia con un plano general de una camioneta familiar que se desplaza por la ruta. Esta situación busca generar conexión emocional y el relato se matiza con tomas que muestran a la familia ajena a la vivencia del conductor, cuando repentinamente el ruido de los frenos y la expresión de temor evidenciarán el choque frontal del que son víctimas. La pantalla se vuelve negra y el target escucha lo que se decide no mostrar: "NO PASA NADA, HASTA QUE PASA". A modo de subtítulo se remata: "SI MANEJÁS, RESPETÁ LOS LÍMITES DE VELOCIDAD Y SEÑALES DE TRÁNSITO".

El segundo spot tiene como objetivo concientizar sobre el riesgo de usar el celular al conducir, mantiene la misma banda sonora del anterior e inicia con una toma desde el interior del vehículo que cumple la función de presentar a los protagonistas una madre joven y a su hijo. Las tomas siguientes la muestran nerviosa ante el sonido de una llamada que atiende y demuestran como fragmenta su atención sin advertir 
un semáforo en rojo. El spot, termina por llevar a negro la pantalla para dejar sólo el ruido del accidente. La pieza suma un nuevo elemento verbal cuando clama: "SI MANEJÁS, NO USES EL CELULAR". La tercera pieza está dirigida a los jóvenes, la primera toma muestra el andar de un vehículo que circula por la noche. El target observará como ambos van intercambiando alcohol y risas, la banda sonora instrumental comparte espacio con la radio del vehículo. Acto seguido, el auto realiza un zigzag y los dos ríen mostrando desconexión con el entorno. La presencia del locutor y texto en pantalla serán idénticas a las demás piezas audiovisuales de la campaña, buscando anclaje con la situación concreta representada: "SI MANEJÁS, NO TOMÉS".

\subsubsection{Análisis de los niveles de creatividad: tabla Ecrep}

1. Originalidad: bajo ( 2 p). Copia todos o la mayoría de los recursos que ya han sido usados. Muestra diferentes escenas en las que los protagonistas sufren accidentes como consecuencia de la imprudencia.

2. Conectividad: bajo $(2 \mathrm{p})$. Conecta ideas cuya relación entre sí es común o predecible.

3. Lógica: bajo (2 p). Resuelve la conexión de ideas distantes entre sí, pero la lógica de conexión es bastante predecible.

4. Impacto: nulo (1 p). No logra la movilización del mundo interno del perceptor.

5. Emotividad: bajo (2 p). No genera ningún tipo de sensación y/o emoción en el público objetivo.

6. Fantasía: nulo (1 p). El perceptor no completa con su imaginación el mundo de fantasía que se le está ofreciendo.

7. Quiebre (1 p): Es convencional el medio y/o soporte: spot publicado en redes sociales y gráficas en vía pública, diarios y revistas de la provincia y redes.

Resultados: Puntaje: 9 puntos. Nivel de creatividad alcanzado: Bajo.

\subsection{Campaña $n^{\circ} 4$}

\subsubsection{Datos técnicos}

1. Nombre de la campaña: Campaña de vacunación antigripal 2017.

Spot genérico: https://www.youtube.com/watch?v=YI0wgYAXSA8

Spot embarazadas: https://www.youtube.com/watch?v=ssE0aYKHh-I

2. Categoría: SALUD.

3. Objetivo: persuadir al target para acuda y se vacune contra la gripe.

4. Concepto: Vacunate contra la gripe.

5. Target: mendocinos mayores de 65 años, embarazadas, madres hasta 10 días después del parto, personal de salud, niños de 6 a 24 meses, enfermos crónicos u obesos. 


\subsubsection{Análisis del contexto}

El Ministerio de Salud de la Nación Argentina promueve un programa de protección a la población de enfermedades prevenibles por vacunas, teniendo como objetivo alcanzar la cobertura del $95 \%$ de vacunas del calendario en todas las jurisdicciones. Dentro del calendario de vacunación está incluido el Plan de Vacunación Anual contra la Gripe.

En consonancia con la política nacional, la campaña de vacunación contra la gripe en Mendoza, está destinada gratuitamente a los grupos de riesgo: mujeres embarazadas, en cualquier momento de la gestación; mujeres puérperas hasta 10 días después del parto (si no se vacunaron durante el embarazo); niños entre 6 y 24 meses inclusive; mayores de 65 años; trabajadores de la salud; niños y adultos que tienen entre 2 y 64 años con enfermedades crónicas -respiratorias, cardíacas, renales, diabetes, obesidad, con receta médica.

En 2017, se previó en la provincia la colocación de más de 300 mil dosis, apuntando a la política de prevención como modo de aumentar la eficiencia del Sistema de salud provincial.

\subsubsection{Análisis de contenido}

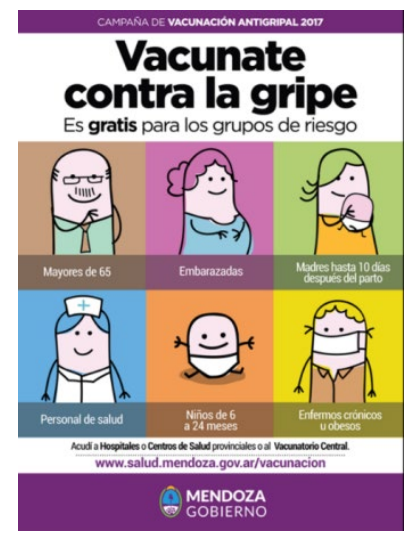

Foto 5. Campaña: Vacunate contra la gripe. Pieza gráfica diarios y revistas. Fuente: Gobierno de Mendoza.

La pieza gráfica en respuesta a un target amplio y heterogéneo resuelve la propuesta mediante la diversidad cromática, este recurso brinda un tono ameno que busca contrarrestar la resistencia del target frente a temáticas vinculadas con la salud. El empleo de la ilustración, actúa en el mismo sentido buscando que el mensaje sea claro, icónico y universal. Los recursos visuales se conjugan persiguiendo el objetivo de movilizar al target para que asuma la conducta deseada. A modo de subtítulo, se señala la gratuidad del servicio como argumento para sostener la propuesta.

El spot para televisión da inicio con una placa que con la voz de una locutora que se presenta joven y de tono cálido, replica: "Mendoza inicia la campaña de 
vacunación antigripal". El espacio central será ocupado sucesivamente por fondos plenos de diferentes colores acompañados por las ilustraciones de los integrantes del target. La locución y el texto en pantalla se encargarán de clarificar los diferentes públicos implicados en la problemática. Hacia el cierre, los personajes están juntos sobre la franja superior de la placa. El segundo spot está centrado en un público objetivo puntual, las embarazadas. Manteniendo los criterios estéticos y compositivos el audiovisual asume un tono interrogativo para conseguir la identificación inicial de un público clave.

Aclaración: la palabra "Vacunate" en castellano rioplatense posee acento prosódico en la sílaba "na" y se diferencia de la palabra "Vacúnate" propia del castellano español.

\subsubsection{Análisis de los niveles de creatividad: tabla Ecrep}

1. Originalidad: nulo $(1 \mathrm{p})$. Copia todos o la mayoría de los recursos, la campaña apela a ilustraciones simplificadas y a la diversidad de colores recursos comúnmente utilizados en campañas de salud pública.

2. Conectividad: nulo (1 p). No conecta ideas ni hace analogías, sólo se ocupa de comunicar un mensaje de forma directa y referencial.

3. Lógica: bajo (2 p). Resuelve la conexión de ideas distantes entre sí, pero la lógica de conexión es bastante predecible.

4. Impacto: nulo (1 p). No logra la movilización del mundo interno del perceptor.

5. Emotividad: bajo (2 p). No genera ningún tipo de sensación y/o emoción en el público objetivo.

6. Fantasía: nulo (1 p). Provoca que el perceptor no complete con su imaginación el mundo de fantasía que se le está ofreciendo.

7. Quiebre (1 p): Es convencional el medio y/o soporte: spot publicado en redes sociales y gráficas en vía pública, diarios y revistas de la provincia y redes.

Resultados: Puntaje: 9 puntos. Nivel de creatividad alcanzado: Bajo.

\subsection{Campaña $n^{0} 5$}

\subsubsection{Datos técnicos}

1. Nombre de la campaña: Cuidá el agua, para que no falte. Año: 2017/2018.

2. Categoría: SOCIEDAD / Ambiente

3. Objetivo: sensibilizar a la sociedad sobre el derroche cotidiano de agua potable, promoviendo su uso responsable.

4. Concepto: Cuidá el agua.

5. Target: hombres y mujeres de 15 a 65 años.

\subsubsection{Análisis del contexto}

Una de las grandes problemáticas de la Provincia de Mendoza está relacionada con el agua, su consumo, su escasez y su cuidado. 
Juan Manuel Lucero (2017, párr.1) desde el periódico "Va con firma Mendoza" analiza lo siguiente:

Desde el verano del año 2009 que la provincia de Mendoza pasa por consecutivas emergencias hídricas. ¿Qué significa y qué implica estar en emergencia hídrica? (...) emergencia hídrica significa que el agua que escurre hacia los ríos de Mendoza transporta un volumen de agua que no superará la media histórica, debido a las escasas nevadas caídas durante los últimos años. Esto se traduce, según los técnicos de Irrigación, en un año hidrológico que variará entre "seco" y "pobre". Considerándose "seco" a los valores de derrame por debajo del $65 \%$ del valor promedio histórico. En cambio, será "pobre" cuando el derrame esté entre el $65 \%$ y $85 \%$, por debajo de la media histórica. (...)

El análisis histórico de la investigadora María Virginia Grosso Cepparo (2017) nos deja ver que la organización del sistema hídrico mendocino, plasmada en la Ley de Aguas de 1884, no sólo fue en la dualidad "oasis - desierto", para empujar la vitivinicultura como explotación económica sino también que estableció derechos y privilegios de agua, en relación con la propiedad privada, beneficiando a algunos y perjudicando a muchos, creando una disputa que se hereda hasta hoy.

\subsubsection{Análisis de contenido}

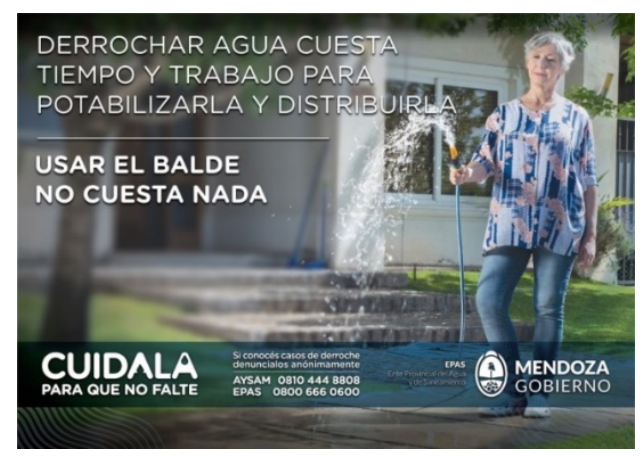

Foto 6. Campaña: Cuidala para que no falte. Pieza gráfica para cartelería exterior.

Fuente: Gobierno de Mendoza.

La campaña está compuesta por gráficas, spot de tv, leds y cartelería exterior. La variedad de medios y soportes buscan una cobertura eficiente del amplio público al cual se dirige esta campaña. Las palabras asumen la denuncia desde un tono directo para indicar la gravedad de la problemática. El empleo de números para indicar la cantidad de litros derrochados en cada situación busca volver tangible la causa y aportar credibilidad al mensaje. En este sentido, los avisos muestran las conductas cotidianas de los ciudadanos haciendo un mal uso del agua. El doble sentido atribuido al término "cuesta" permite generar una comparación marcando la complejidad de la temática en oposición al fácil camino para solucionarla. El espacio inferior está ocupado por un sócalo azul y se le pide al público: “CUIDALA PARA QUE NO FALTE”. El valor cromático de la campaña tiene un rol referencial, el azul 
indiscutiblemente vinculado al agua y de presencia recurrente en campañas que buscan su preservación está presente en fondos, textos y vestimenta de los protagonistas. De esta forma, su empleo persigue el objetivo de ser vinculado de forma directa con la temática de la comunicación, al tiempo que sirve a fines estéticos.

En castellano rioplatense, el imperativo "Cuida" se acentúa en la última sílaba: "Cuidá", mientras que "Cuídala" posee acento prosódico en la segunda sílaba: "da".

\subsubsection{Análisis de los niveles de creatividad: tabla Ecrep}

1. Originalidad: bajo (2 pts). Copia ciertos recursos: presencia del ciudadano cometiendo un acto que se busca desalentar, situaciones cotidianas, código cromático referencial en alusión al agua.

2. Conectividad: nulo (1 pt). La campaña no vincula ideas distantes, sólo se limita a comunicar un mensaje referencial, claro y directo.

3. Lógica: nula (1 pt). No presenta ninguna vinculación de ideas lejanas (analogía).

4. Impacto: nulo (1 pt). No logra movilizar el mundo interno del perceptor.

5. Emotividad: nulo (1 pt). La campaña genera sensaciones negativas, amparada por imágenes y textos que culpabilizan al target por su accionar.

6. Fantasía: nulo (1 pt). Las piezas analizadas muestran un mensaje directo y transparente, que no implica al target como constructor de sentido.

7. Quiebre: (1 pt). Es convencional en el uso de sus medios y soportes.

Resultados: Puntaje: 8 puntos. Nivel de creatividad alcanzado: nulo.

\subsection{Campaña $n^{\circ} 6$}

\subsubsection{Datos técnicos:}

1. Nombre de la campaña: Grooming. Año: 2018.

2. Categoría: SOCIEDAD.

3. Objetivo: alertar a los padres de niños y adolescentes sobre los riegos del "grooming".

4. Concepto: protejamos a los chicos del grooming.

5. Target: hombres y mujeres mendocinos, padres de niños y adolescentes.

\subsubsection{Análisis del contexto:}

El gobierno escolar de la Provincia de Mendoza (DOAITE, 2018) arroja la siguiente definición de Grooming:

(...) una acción deliberada por parte de un adulto que procura acosar sexualmente a un niño, niña o joven mediante el uso de tecnologías de la información y comunicación. Siempre es un adulto quien ejerce el grooming. (...) Estos adultos suelen generar un perfil falso en una red social, sala de chat, 
foro $\mathrm{u}$ otro, en donde se hacen pasar por un chico o una chica y entablan una relación de amistad y confianza con el niño o niña que quieren acosar $(\ldots)^{\prime \prime}$.

Establece tres momentos, de contacto y acercamiento; Se busca ganar confianza, confesando cuestiones íntimas, promoviendo el envío de fotos; y el tercer momento es el ciberacoso por el cual el adulto utiliza el material sobre el chico y chantajea buscando encuentros personales.

En cuanto a las medidas que toma el Estado argentino para combatir esta problemática, encontramos que el 13 de noviembre de 2013, a partir de la Ley 26.904 se incorporó al Código Penal argentino el artículo 131 que establece una pena de prisión de seis meses a cuatro años para este delito. En consonancia, en octubre de 2018, se promulgó desde el Senado de la Nación Argentina la Ley 27458 que declara al 13 de noviembre como Día Nacional de la Lucha contra el Grooming.

\subsubsection{Análisis de contenido}

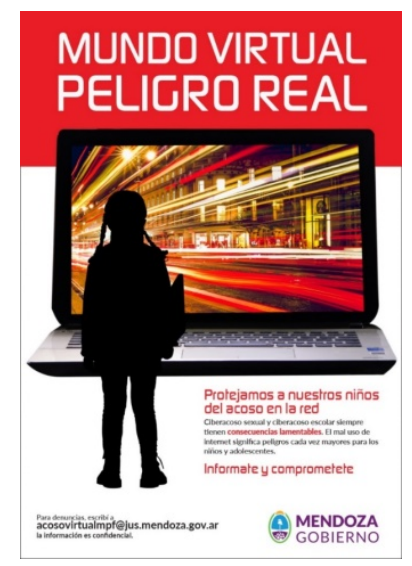

Foto 7. Campaña: Mundo virtual, peligro real. Pieza gráfica diarios y revistas.

Fuente: Gobierno de Mendoza.

Las piezas audiovisuales incorporan la presencia de un niño y una adolescente que, asumiendo el rol de presentadores, se ocupan de hablarle a sus pares sobre los riesgos en el uso de internet. Siguiendo este enfoque, los protagonistas miran a cámara emulando una comunicación "uno a uno" con interpelación directa. En el primer spot, la adolescente que durante todo el relato sostiene un smartphone, inicia el discurso señalando que "En las redes te ven tus amigos, pero también mucha gente que no conocés". Sus palabras son apoyadas por una ilustración vectorial en color rojo que gira sobre el costado izquierdo de la pantalla, e ilustra la idea de "redes". Cada una de tales acciones es apoyada visualmente por un ícono rojo que luego es señalado como "negativo", anteponiéndole un ícono de "dislike" en color negro. El concepto de "peligro". El segundo spot es protagonizado por un niño que inicia con las palabras "Hablar con extraños no está bueno". Esta conducta preventiva es resuelta visualmente, cuando el niño sujeta el ícono (representando al agresor) y lo arrastra hacia una papelera. 
El aviso gráfico replica el código de los spots para sumar un titular que destaca desde la parte superior de la página: "MUNDO VIRTUAL. PELIGRO REAL". En este sentido, la comparación es empleada desde la redacción para oponer los dos mundos que el mensaje busca vincular conceptualmente. Un subtítulo, en color rojo, sostiene la primera persona del plural para hacer un pedido colectivo a implicar a un "nosotros": "Protejamos a nuestros niños del acoso en la red". El mal uso de internet significa peligros cada vez mayores para los niños y adolescentes". De este modo, la campaña que hasta el momento había centrado sus esfuerzos en el "grooming", equipara la problemática a lo sucedido en el "ciberbullying". Sin profundizar en sus dinámicas y diferencias, el copy remarca mediante el empleo de tipografía bold roja, las "consecuencias lamentables" e irremediables de ambos fenómenos sociales.

\subsubsection{Análisis de los niveles de creatividad: tabla Ecrep}

1. Originalidad: bajo ( 2 pts). La campaña mantiene un tono y recursos que repiten lo conocido.

2. Conectividad: bajo (2 pts). Conecta ideas cuya relación entre sí es común o predecible: la "desprotección" a la que se someten los niños en internet y el acoso al que se exponen.

3. Lógica: bajo ( 2 pts). Resuelve la conexión de ideas distantes entre sí, pero la lógica de conexión es bastante predecible.

4. Impacto: nulo (1 pt). Si bien el spot muestra un elemento diferenciador, los demás audiovisuales y la gráfica presentan propuestas impostadas que no logran involucrar.

5. Emotividad: nula (1 pt). Lejos de generar implicación hacia el mensaje, propone recursos que generan distanciamiento.

6. Fantasía: nulo (1 pt). La débil conexión de escenarios (desprotección virtual real), sólo encuentra lugar en la pieza televisiva.

7. Quiebre: (1pt). Es convencional el medio o soporte.

Resultados: Puntaje: 10 puntos. Nivel de creatividad alcanzado: nulo.

\subsection{Campaña $n^{0} 7$}

\subsubsection{Datos técnicos}

1. Nombre de la campaña: No compres robado. Año: 2018.

2. Categoría: SOCIEDAD.

3. Objetivo: concientizar al target sobre su rol necesario en el circuito delictivo, desestimando la compra de productos robados y motivando su denuncia de casos sospechosos.

4. Concepto: No compres robado.

5. Target: mendocinos de 15 a 55 años de edad. 


\subsubsection{Análisis del contexto}

En cuanto al comercio ilegal de bienes robados, Fernando Carrión (2018) explica que luego de robados, los objetos deben entrar al mercado, explicando que para ello hay un sistema económico que lo sustenta; circuitos según el tipo de objetos. El autor considera que lo más eficaz para combatir este tipo de delitos es atacar todas las fases del ciclo económico del mercado ilegal, que comienza con la sustracción, luego con intermediarios que hacen llegar los objetos hacia su destino. También, señala que en conjunto con este delito aparecen otro tipo de delitos como la evasión de impuestos, transporte ilegal, etc.

La Confederación Argentina de la Mediana Empresa (CAME) de Argentina realizó el Mapa Nacional de la Ilegalidad, en 2017, señala que la mayor parte del comercio ilegal se lleva adelante a través de "saladitas" y "manteros" aunque crece de manera indefinida la venta informal a través de redes sociales como Facebook y WhatsApp.

\subsubsection{Análisis de contenido}

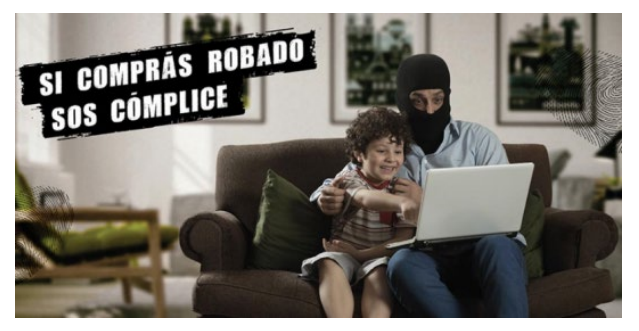

Foto 8. Campaña: No compres robado. Pieza gráfica cartelería exterior. Fuente: Gobierno de Mendoza.

Las gráficas se valen del realismo que aporta el uso de la fotografía para presentar una comparación. Sobre las figuras recae el peso retórico del mensaje y el pasamontañas incurre en una sinécdoque: tal elemento sugiere el concepto "delincuencia" y toda la cadena delictiva que permitió conseguir los productos. El contraste entre la naturalidad de la escena cotidiana y el elemento intruso, se constituye como el eje creativo para impactar al target. Los titulares dispuestos de manera oblicua, optan por el tono directo e imperativo: "SI COMPRÁS ROBADO SOS CÓMPLICE". Palabras que buscan implicar al target para hacerlo cargo de su responsabilidad y recursos gráficos que sugieren la sordidez del mundo de la delincuencia. Las primeras dos tomas de los audiovisuales permiten al target observar a una integrante de policía científica que se coloca los guantes y prepara su material de trabajo. De esta forma los segundos introductorios adelantan al público lo que habrá de presentarse, una escena del crimen. La ausencia de diálogos, permite que el espectador focalice su atención en las personas, los hechos y objetos del relato. Una serie de planos y contra-planos permiten observar la interacción entre los profesionales y detrás de ellos, la cinta que marca la escena del crimen incluye el concepto de campaña: "NO COMPRES ROBADO". Sobre la esquina superior izquierda, hace su ingreso un texto que es acompañado por el locutor de campaña: 
“LO QUE VOS COMPRÁS BARATO A OTRO LE COSTÓ CARO”. Todos los spots mantienen el mismo código, exploran el lado retórico del mensaje mediante una hipérbole. El impacto creativo está sujeto a la exageración de ciertos delitos considerados menores, mostrándolos como si se tratara de un crimen cometido hacia una persona.

En castellano rioplatense el verbo "compras" se acentúa en la última sílaba: "Comprás".

\subsubsection{Análisis de los niveles de creatividad: tabla Ecrep}

1. Originalidad: medio (3 pts). Posee algunos recursos que por su rareza son diferenciadores, personas vistiendo pasamontañas, generando destaque dentro de escenas "cotidianas" y conocidas; objetos como víctimas de escenas del crimen.

2. Conectividad: bajo (2 pts). Conecta ideas cuya relación entre sí es predecible. El aspecto delictivo es presentado mediante escenas del crimen.

3. Lógica: bajo (2 pts). Resuelve la conexión de ideas distantes entre sí, pero la lógica de conexión es bastante predecible.

4. Impacto: bajo (2 pts). Logra movilizar débilmente el mundo interno del target, al presentar un mensaje con un elemento diferenciador que lo interpela.

5. Emotividad: mediano (3 pts). Genera sensaciones y/o emociones con las que el público objetivo se identifica livianamente: preocupación y culpa.

6. Fantasía: alto (4 pts). Provoca que el perceptor complete con su imaginación el mundo de fantasía que le está ofreciendo, vinculado con la causa social que se comunica.

7. Quiebre: (1 pt). Es convencional en el uso del medio y soporte.

Resultados: Puntaje: 17 puntos. Nivel de creatividad alcanzado: Bajo.

\subsection{Campaña $n^{0} 8$}

\subsubsection{Datos técnicos}

1. Nombre de la campaña: Consumir de más, no va más. Año: 2018.

2. Categoría: SOCIEDAD/ Ambiente/ Consumo responsable.

3. Objetivo: Concientizar al target sobre el consumo responsable del gas.

4. Concepto: Consumir responsablemente nos beneficia a todos.

5. Target: Hombres y mujeres desde los 18 años, residentes en la Provincia de Mendoza.

\subsubsection{Análisis del contexto}

Según el artículo realizado por Guillermina Jacinto y Silvina Carrizo (2018), que analizan la relación entre energía y pobreza en la Argentina: 
Disponer de servicios energéticos seguros, eficientes y de calidad es fundamental para el bienestar y la equidad social. (...)El 60\% de los hogares de la Argentina está conectado a las redes de gas natural y utiliza este combustible para la cocción. También se lo aprovecha para el calentamiento de agua sanitaria y la calefacción. Considerando gas natural y GLP, el porcentaje de familias que usan gas es de un $97 \%$. El 3\% de los hogares aún utiliza leña para cocinar, es decir más de un millón de personas. (Jacinto, Carrizo, 2018, párr.1)

Carlos Manzoni y Pablo Bernasconi (2018) aseguran que Argentina consume más gas natural que cualquier otro país en América Latina.

En este marco, durante 2017 y 2018, se realizó en Argentina la quita de subsidios a las tarifas de servicios energéticos como el gas y la energía eléctrica, produciéndose los llamados tarifazos que incrementaron en gran magnitud los precios que los consumidores finales de servicios deben pagar por ellos.

Entre las consecuencias de estas decisiones de Estado, encontramos el aumento de la pobreza, directamente relacionado por la restricción económica a la utilización de servicios básicos y, por supuesto, la caída del consumo.

Por otra parte, hay que tener en cuenta la concepción del Estado en torno a la Eficiencia energética, desde el Ministerio de Energía y Minería de la Presidencia de la República Argentina se difunde lo siguiente:

La energía es fundamental para la vida humana y el desarrollo de los países, pero también es un recurso escaso en todo el mundo. La Eficiencia Energética es una práctica/forma de gestionar el crecimiento de la energía, obteniendo un resultado igual con menor consumo o un resultado mayor consumiendo lo mismo (...)

\subsubsection{Análisis de contenido}
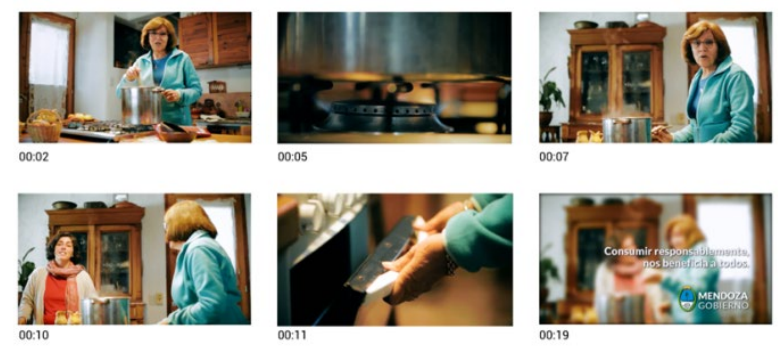

Foto 9. Campaña: “Consumir de más, no va más". Comercial televisión. Fuente: Gobierno de Mendoza.

Las protagonistas ofrecen un mensaje, a medio camino entre los géneros testimonial y presentación, en el que les sugieren a otras mujeres diversas formas 
cotidianas de ahorrar. De esta forma, lo que "no va más" es el consumo excesivo sin conciencia. El mensaje, de tono cercano y positivo, ha sido reforzado por una banda instrumental que progresivamente aumenta su intensidad. En este sentido, las palabras amplían las recomendaciones, finalmente una voz en off femenina con tono joven y cálido cierra el mensaje: "Consumir responsablemente, nos beneficia todos". El cierre del spot se viste de los recursos que serán sostenidos en todos los audiovisuales escena desenfocada, locutora cálida y texto en pantalla que aporta el cierre. Cada pieza asume la responsabilidad de comunicar determinadas conductas recomendadas. En busca de identificación, se opta por variar los protagonistas: mujeres de diferentes edades, un hombre y un joven son los encargados de hablarle "de igual a igual" al target. La elección del enfoque y el tono cálido no quita cierto aire "imperativo" en las expresiones verbales y no verbales de los personajes: seriedad, miradas fijas y gestos con las manos, las palabras profundizan tal sentido: "regulá", "cerrá", "apagá", "bajá”, entre otras. Todos estos imperativos verbales se corresponden con la pronunciación propia del castellano rioplatense.

\subsubsection{Análisis de los niveles de creatividad: tabla Ecrep}

1. Originalidad: bajo (2 pts). El enfoque creativo y los recursos empleados son ya conocidos por el target. Las situaciones de la vida cotidiana de los distintos personajes mostrados no le permiten a esta campaña tener un despegue creativo mayor.

2. Conectividad: bajo (2 pts). Conecta ideas cuya relación entre sí es común o predecible. Este recurso es utilizado con la intención de lograr un alto grado de identificación con el target.

3. Lógica: bajo (2 pts). Resuelve la conexión de ideas distantes entre sí, pero la lógica de conexión es bastante predecible. Esto se ve reflejado en un enfoque referencial y el empleo del género testimonial.

4. Emotividad: mediano ( 3 pts). Genera sensaciones y/o emociones con las que el público objetivo se identifica livianamente: preocupación y culpa.

5. Impacto: bajo (2 pts) .Tiene unos pocos recursos que logran movilizar débilmente con una serie de testimonios.

6. Fantasía: nulo (1 pt). El perceptor no está invitado a completar con su imaginación el mundo de fantasía que se le está ofreciendo, el cual se plantea de forma tímida (desde el uso del recurso) y espontánea (desde la actuación de los personajes).

7. Quiebre (1 pt): Es convencional el medio y/o soporte: spot publicado en redes sociales y YouTube.

Resultados: Puntaje: 13 puntos. Nivel de creatividad alcanzado: Bajo.

\subsection{Focus Group}

Trabajamos en tres focus group de 10 personas cada uno, integrantes voluntarios entre 18 y 65 años, de distintos niveles educativos y clases sociales, representativos del público objetivo de las campañas. 
En relación con la preferencia de campaña, la más elegida fue "No compres robado"; luego continuaron "Grooming", "Familia Temporaria; "Cuidá el agua" y "Acoso callejero"; "Vacunate" y "Tránsito"y por último "Consumir de más no va más".

En cuanto a los niveles de Recordación, el más alto fue "Grooming", seguido por "No compres robado"; "Familia Temporaria"; "Acoso callejero" y "Cuidá el agua"; "Consumir demás no va más" y "Vacunate". Los niveles de recordación fueron medidos 15 días después de cada Focus.

Internet y Tv fueron los medios más elegidos, luego vía pública, destacándose la no elección de diarios. El recurso de mayor impacto fue el del "niño sin familia", seguido por el "pasamontañas y la música"; luego las imágenes; y por último el tema y la voz del locutor.

En cuanto a la opinión sobre las campañas de bien público, 23 personas contestaron que ayudan mucho, 7 personas que no siempre ayudan, 1 que ayudan poco, y ninguno respondió que no ayudan nada.

En cuanto a la pregunta abierta “¿Por qué?" las respuestas fueron: porque nos hacen tomar conciencia de algunos temas; porque tocan temas importantes de forma creativa y entretenida; nos ayudan a darnos cuenta; son muy importantes para empezar a pensar en una sociedad mejor; es la única forma de que cambiemos algunas costumbres que no están bien, como manejar y usar el celular.

\section{CONCLUSIONES}

El relevamiento de la muestra postuló al Gobierno como principal anunciante fiel a su función social realiza una lectura de las problemáticas sociales y genera campañas para dar respuesta al contexto. Los temas prioritarios se centran en dos categorías: Salud y Sociedad. El análisis de contenido permitió comprender que se articulan mensajes generalistas, teniendo en cuenta que los presupuestos son ajustados y las problemáticas transversales, se generan campañas multitarget. Ante esta situación, el reconocimiento de la heterogeneidad del público se observa especialmente en campañas como "No compres robado" o "Consumir de más, no va más", en las que se registra una variación de sexo y edad de los protagonistas con una ligera adaptación del código y no acciones especialmente dirigidas a cada uno de los segmentos. Esta concepción de un público excesivamente genérico sumado a un enfoque racional del mensaje se opone a la tendencia publicitaria actual que profundiza en la diversidad de los públicos y en el valor de la emoción para generar compromiso social. El discurso pone énfasis en el problema o en la solución, sin embargo, muchas piezas culminan "responsabilizando" al target otras "culpabilizan" su accionar como el desencadenante de situaciones como "No pasa nada, hasta que pasa" y "No compres robado". No se busca persuadir sino disuadir al público para que abandone conductas nocivas. Lejos de un enfoque participativo y dialogado las piezas están construidas desde una mirada clásica con mensajes unidireccionales. 
Este tipo de mensajes resultan con muy bajos niveles de creatividad al medirlos con la tabla Ecrep, del total de campañas más de la mitad registran un "nivel nulo" de creatividad, la que obtuvo el mejor puntaje fue a su vez la más elegida por los participantes del focus, una muestra clara que la creatividad también debe ser protagonista en el bien público. La selección de medios queda circunscripta a los tradicionales, sin observarse otras instancias complementarias que exploren el valor de la participación activa del target. El mejor de los casos fue el empleo de las redes sociales que instan a compartir una publicación y el hashtag de campaña ("Acoso callejero"). El cruce de soportes refleja la preocupación del anunciante por impactar al target completo, se observa, además, una mayor frecuencia de exposición lo cual es positivo y se ve reflejado en los resultados de los focus group que muestran altos niveles de recordación y siguen marcando la predisposición del público hacia mensajes de corte social que colaboren con la toma de conciencia. En esta instancia quedó de manifiesto que el cambio actitudinal se produce a corto plazo y en paralelo con la emisión de las campañas. Si se destinaran esfuerzos para incorporar estas temáticas en tiempos y espacios de ocio donde lo artístico y recreativo constituye un marco efectivo se lograría aumentar el impacto social.

"El papel de la publicidad como institución social está evolucionando, para el caso de la publicidad que me ocupa, hacia un papel más relacionado con la acción social. Se está pasando de la publicidad como institución social a la publicidad como agente social, como elemento de la acción social al servicio del cambio racional, con capacidad para contribuir a la mejora de la sociedad, de los grupos y de las personas". (Alvarado López, 2003, p. 691).

\section{REFERENCIAS}

Alvarado López, M. (2009). La publicidad social: una modalidad emergente de comunicación. (Tesis de doctorado). Universidad Complutense de Madrid, Madrid, España. Recuperado de http:/ / eprints.ucm.es/11522/1/T27111.pdf

Alvarado López, M. (2009). ¿Publicidad Social?: usos y abusos de "lo social" en la publicidad. Revista ICONO14 Revista Científica De Comunicación Y Tecnologías Emergentes, 7(2), 125-151. https://doi.org/10.7195/ri14.v7i2.320

Asociación civil "Luchemos por la vida" (2017). Consideraciones generales acerca de los accidentes de tránsito. Buenos Aires, Argentina. Recuperado de https://www.luchemos.org.ar/es/accidentes-argentina

AVOME. (2017). Programa de Familia Temporaria. Mendoza, Argentina. Recuperado de http:// www.avome.org/index.php/2017/05/05/programa-de-familiatemporaria/

CAME (2017). Mapa Nacional de Ilegalidad Comercial: hay 587 saladitas en el país y 91.530 vendedores ilegales. Buenos Aires, Argentina. Recuperado de http://www.redcame.org.ar/contenidos/comunicado/Mapa-Nacional-de- 
Ilegalidad-Comercial_-hay-587-saladitas-en-el-pais_br_-y-91_530-vendedoresilegales.1471.html

Carrión, F. (2008). Los bienes robados. Diario Hoy. Recuperado de https://works.bepress.com/fernando_carrion/205/

Ley 26904. (2013). Congreso de la Nación Argentina. Recuperado de http://servicios.infoleg.gob.ar/infolegInternet/anexos/220000224999/223586/norma.htm

Ley 27458 (2018). Congreso de la Nación Argentina. Recuperado de http://servicios.infoleg.gob.ar/infolegInternet/anexos/315000319999/316381/norma.htm

Coordinación Provincial de Educación Sexual Integral de la DOAITE, Dirección General de Escuelas, Mendoza (2018). ¿Qué es el grooming? Recuperado de: http://www.mendoza.edu.ar/que-es-el-grooming/

Consejo Publicitario Argentino (2011). La Publicidad de Bien Público. Buenos Aires, Argentina: Temas Grupo Editorial.

Grosso Cepparo, M. V. (2017). Agua y tierras secas: Lecturas críticas sobre la escasez hídrica en el departamento de Lavalle (Mendoza, Argentina). Estudios Socioterritoriales, 22. Recuperado de http:/ / www.scielo.org.ar/scielo.php?script=sci_arttext\&pid=S1853$\underline{43922017000200003 \& \operatorname{lng}=\mathrm{es} \& \ln g=\mathrm{es}}$

Jacinto, G. y Carrizo, S. (2018). Energía y pobreza en la Argentina. Petrotecnia. Buenos Aires, Argentina. Recuperado de http://www.petrotecnia.com.ar/junio18/Petro/EnergiaPobreza.pdf

Lucero, J. M. (2017). Mendoza afronta su octavo año con crisis hídrica. Va con firma Mendoza. Argentina. Recuperado de

http://vaconfirmamendoza.com.ar/?articulos/id_4055/mendoza-afronta-suoctavo-ano-con-crisis-hidrica

Lui, A. (2017). Ex Dinaf: cómo se revinculan los hermanos separados en hogares. Diario El Sol. Mendoza, Argentina. Recuperado de https://www.elsol.com.ar/exdinaf-como-se-revinculan-los-hermanos-separados-en-hogares.html

Manzoni, C. y Bernasconi, P. (2018). El gas fluye por los hogares argentinos. Diario La Nación. Buenos Aires, Argentina. Recuperado de https://www.lanacion.com.ar/economia/el-gas-fluye-por-los-hogaresargentinos-nid2098296 
Ministerio de Transporte de la Nación. Seguridad Vial (2018). Situación de la Seguridad Vial en Argentina. Datos y análisis integral del problema. Buenos Aires, Argentina. Recuperado de https://www.argentina.gob.ar/sites/default/filessituacion_de_la_seguridad_vial en_la_argentina_25.06.pdf

Vejling, L., Tomba, C. \& Mateo, A. (2014). La esencia creativa de la publicidad. Mendoza, Argentina: Editorial UMaza.

Vivanco, R. (Coord.) (2017). Violencia contra las mujeres en el espacio público: La inseguridad de la que nadie habla. Mumalá. ISEPCI. Recuperado de http://www.enperspectiva.com.ar/wpcontent/uploads/2017/09/OBSERVATORIO-07.pdf

\section{AUTORES:}

\section{Carolina Tomba}

Licenciada en Comunicación Social y Especialista en Docencia de Nivel Superior, desarrollando la Tesis de Maestría en Docencia en Nivel Superior. En el ámbito de la investigación me desempeño en el área de Publicidad, Comunicación y Ciencias Sociales. Como directora, llevé adelante tres proyectos de investigación: "Repensar la Publicidad del Siglo XX desde una perspectiva socio histórica"; "La responsabilidad social de la publicidad: eficacia de las campañas de bien público" y "La responsabilidad social de la publicidad: el rol de las campañas de bien público". Actualmente me desempeño como Secretaria Académica de la Facultad de Comunicación de la UMaza, como directora de tesis de grado y como docente titular en la Licenciatura en Publicidad.

ctomba@umaza.edu.ar

Orcid ID: https:/ / orcid.org/0000-0003-0472-7875

Google Scholar: https://scholar.google.com/citations?user=JAbreEYAAAAJ\&hl=es

\section{María Cecilia Muñoz}

Profesora de Grado Universitario en Historia, graduada en la Facultad de Filosofía y Letras, de la Universidad Nacional de Cuyo. Me desarrollo como docente en el Nivel Universitario, como adjunta en la cátedra de Historia de las Ideas Políticas Modernas y Contemporáneas para las Licenciaturas en Publicidad y Comunicación; y como titular en la cátedra de Historia de la Publicidad, para la Licenciatura en Publicidad. También me desempeñé en el área de Ciencias Sociales, Comunicación y Publicidad, como Investigadora Principiante en el trabajo de Investigación "Repensar la Publicidad del siglo XX desde una perspectiva socio-histórica" junto con la Lic. Carolina Tomba y el Lic. Andrés Allisiardi, finalizado en 2014 y con el mismo equipo de investigación, como Investigadora Asociada en el trabajo: "La responsabilidad social de la Publicidad: Efectividad de las Campañas de Bien Público"; y en 2015, "La responsabilidad social de la publicidad: el rol de las campañas de bien público".

cmunoz@umaza.edu.ar

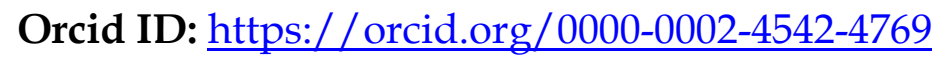




\section{Andrés Adriano Allisiardi}

Licenciado en Publicidad, me dedico a la comunicación publicitaria y corporativa. Además exploro la realidad publicitaria desde la docencia e investigación, en aspectos claves como el estudio de los mensajes y su impacto en la esfera social. Me desempeño como docente en diferentes cátedras pertenecientes a la Lic. en Publicidad en la UMaza. En investigación, participé como Becario en el trabajo "Repensar la Publicidad del siglo XX desde una perspectiva socio-histórica" y como Investigador en "La responsabilidad social de la Publicidad: Efectividad de las Campañas de Bien Público".

allisiardi@umaza.edu.ar

Orcid ID: http:/ / orcid.org/0000-0003-4813-1571

Google Scholar: https://scholar.google.es/citations?user=0FIkzq4AAAAJ\&hl=es 